\title{
El Aprovechamiento de las aguas en la Ley de 13 de junio de 1879. Trayectoria de un texto legislativo a la luz de la optimización y eficacia de los recursos hídricos.
}

\author{
Francisco José Abellán Contreras \\ Universidad de Alicante \\ fjac3@alu.ua.es
}

\begin{abstract}
Resumen. El aprovechamiento de las aguas en la Ley de 13 de junio de 1879 es una cuestión trascendental para comprender la transformación de la economía que experimentó España a mediados del siglo XIX, especialmente en la economía agraria, gracia en gran parte a la expansión de los riegos. En este sentido, el legislador español en el Real Decreto de 29 de abril de 1860, dejó planteado la necesidad de un cambio en la política agraria de la Nación, cambio que giraría en tono a la expansión del riego. Dos fueron los textos legales que contribuyeron a este cambio; las Leyes de Aguas de 3 de Agosto de 1866 y de 13 de junio de 1879. Estos textos legales se han tomado como fundamento teórico sobre el que desarrollar este artículo.
\end{abstract}

Palabras clave. Legislación, uso, gestión, agua, regadío.

\begin{abstract}
The use of water in the Ley de 13 de junio de 1879 is the main issue to understand the socio-economic development of Spain in the late nineteenth century, focused on a change into the agrarian economy. This paper takes as its starting point the Real Decreto de 29 de abril de 1860, where the legislator proposed a change in agricultural policy of the country, settled in the traditional system of dry farming, for irrigated agriculture. There were two legal texts that contributed to this development: the Ley de Aguas de 3 de agosto de 1866 y de 13 de junio de 1879. Both of them are the legal sources for the theoretical study as a basis for the development of this paper.
\end{abstract}

Keywords. Use, management, water, irrigation, law.

\section{Introducción}

El agua es una riqueza colectiva que debe destinarse especialmente a la satisfacción de las necesidades generales de cualquier territorio. Este recurso natural se nos presenta como un elemento vital para el desarrollo de toda forma de vida, y además nos permite conocer y comprender el presente, pasado y futuro de las sociedades. Pero hay que advertir, que del mismo modo que el líquido elemento es fuente de vida, de prosperidad, bienestar y progreso para el nacimiento y desarrollo de una civilización, supone de igual modo un peligro que amenaza a la sociedad y sus intereses. Los avances técnicos y tecnológicos en el campo de la hidráulica, desde sus orígenes en tiempos de los romanos hasta nuestros días, ha posibilitado un aprovechamiento eficiente y justo de los recursos hídricos disponibles en cada región y los criterios que regulan su uso y disfrute han condicionado en gran medida la forma de vida de una sociedad. "Los recursos disponibles, la tecnología que permite su aprovechamiento y los criterios que regulan su uso y disfrute condicionan definitivamente la forma de vida a lo largo de la Historia” (López y Melgarejo, 2002). Lo que en tiempos pasados era una cuestión elemental para la subsistencia misma de un pueblo y su cultura, lo es en los tiempos actuales, en la medida en que conocer y aplicar las bondades que supone hacer un buen uso y una correcta distribución de las aguas, así como aprovechar eficientemente los recursos hídricos, es transcendental para el buen desarrollo socioeconómico de cualquier territorio. 
Por tanto, distribución eficiente, aprovechamiento óptimo y buen uso de las aguas públicas, son aspectos que preocupan en la actualidad, debido en gran parte a la creciente ansiedad del ser humano por proteger, preservar y salvaguardar los recursos hídricos de la sobreexplotación, del desaprovechamiento y mal uso del líquido elemento. Si bien, tal preocupación por la optimización de los recursos hídricos, así como por su adecuado aprovechamiento y distribución equitativa, tiene un largo recorrido en la historia de nuestro país. Se trata de una cuestión "atemporal" pues ya la gran civilización romana dejó en la Península Ibérica un importante legado arquitectónico en cuanto a obras hidráulicas se refiere, con el fin de canalizar, abastecer y distribuir de forma justa el líquido elemento, fijando para ello, reglas de buen uso y sancionado toda conducta humana que de forma dolosa o imprudente supusiera un perjuicio o menoscabo al derecho de un particular al uso común de las aguas públicas. Tanto el pueblo romano en la Edad Antigua, como el árabe en la media, pusieron un esmerado cuidado en abastecer sus centros de población de abundante agua potable, para satisfacer con ella la multitud de necesidades que su floreciente civilización requería, y en este sentido, en la legislación foral de Granada podemos encontrar multitud de disposiciones referentes a la infinidad de aplicaciones del agua a las necesidades urbanas. La comunidad árabe dejó tantos y tan variados testimonios culturales que por ello no podemos ni debemos obviar su importante labor en el ramo de las aguas.

Es precisamente en el ámbito de la agricultura donde apreciamos con mayor profundidad su sello e impronta, ya que esta comunidad puso en práctica sus sistemas de cultivos, dando al regadío un papel predominante y destacado, gracias en gran parte al dominio de los trabajos en el campo de la hidráulica, lo que permitió el buen aprovechamiento de las aguas en los riegos de los campos, viéndose favorecido esta labor por la llamada "ética de las aguas", es decir, llevar a cabo un uso racional y justo del líquido elemento para ser ésta aprovechada y distribuida de forma eficiente para su disfrute comunal (Martínez Almira, 2014). No son pocas las obras destinadas al aprovechamiento y correcta distribución de las aguas las que se practicaron en tiempos de la dominación árabe, ya que se hicieron infinidad de derivaciones en diferentes ríos, se levantaron presas, se construyeron pantanos y canales de riegos en varias provincias de la Península (muy especialmente en las zonas del sureste peninsular, Valencia, Alicante, Murcia y Sur de Andalucía).

Con objeto de facilitar el riego de los campos, proliferaron la construcción de acequias, azudes, azarbes, embalses, aljibes, pozos, entre otros, (Box Amorós, 1992) y ese elevado número de obras destinadas a la contención, abastecimiento, canalización y distribución de las aguas, trajo consigo la necesidad de regular los derechos y también las obligaciones que se generaban respecto al aprovechamiento de las mismas. En este sentido, a mediados del siglo XIX, el legislador español preocupado por dar una solución a esta cuestión legal de viejo cuño, la de regular los derechos y obligaciones que se derivan del dominio y aprovechamientos de las aguas, elaboró la Ley de Aguas 3 de agosto de 1866. Hasta la citada Ley, las reseñas a los distintos aprovechamientos de las aguas, se contenían en numerosas normas dispersas, dando como resultado una pluralidad de normas, con escasa conexión entre si y carentes de una sistemática coherente, lógica y práctica (Álvarez Fernández, 2004). En este sentido se pronunció el Decreto de 27 de abril de 1859, por el que se nombra a la Comisión encargada de redactar un Código General de las Aguas, cuya necesidad resultaba necesario a consecuencia ${ }^{1}$ "de la multitud de documentos legales que hoy rigen, excesivos por su número, incompletos en su contenido, diseminados entre las demás partes de la legislación patria, contradictorias a veces, con frecuencia confusos, faltos

\footnotetext{
${ }^{1}$ Véase el Decreto de 27 de abril de 1859.
} 
siempre de unidad como procedentes de diversas épocas y de sistemas de gobierno y de civilizaciones radicalmente distintas."

Con esta Ley de Aguas de 1866 se permitió dar luz a cuestiones hasta la fecha vacías de regulación, que ni las leyes civiles ni administrativas de la época se habían preocupado de tratar, como por ejemplo las relativas a la regulación de las aguas subterráneas. Fijó las reglas en torno al dominio y/o derecho de propiedad de las aguas, permitiendo diferenciar entre aguas de dominio público y aguas de dominio privado. Aceptó el principio del dominio público de las aguas que concurren por sus cauces naturales, se dio por tanto, garantías al dominio particular, y en definitiva, se asentaron las bases en cuanto a los derechos de propiedad de las aguas, ya fueren éstas para uso público o uso particular De igual modo, fijó las reglas entorno al aprovechamiento de las aguas, diferenciando así, entre los aprovechamientos comunes y los especiales de aguas públicas. Estableció también como necesaria la servidumbre de acueducto, dando reglas precisas para su aplicación, y se preocupó de fijar los pilares entorno a la administración y buen funcionamiento de determinados organismos, tales como; la Comunidad de Regantes, los Sindicatos y Jurados de las aguas. Para velar y vigilar por el correcto uso y aprovechamiento de las aguas destinadas al riego por parte de los miembros de la Comunidad de Regantes, la Ley de Aguas se preocupo de trazar el mapa competencial y funcional de la policía de las aguas. Por último, y no por ello menos importante, procuró deslindar la competencia de la jurisdicción en materia de aguas.

Si bien, pese a la enorme importancia que tuvo esta Ley para el desarrollo socioeconómico de España de mediados del XIX, hubo necesariamente de ser reformada. Tal reforma obedeció en principio a la necesidad de fijar límites en cuanto a la regulación y estudio de las aguas. Ello supuso la aparición de la nueva Ley de Aguas de 13 de junio de 1879. Ésta comprende todas las disposiciones relativas a las aguas, es decir, es una ley general sobre la materia y no sólo una ley especial sobre el aprovechamiento de las aguas públicas. Se halla claramente animada por el deseo de restringir los derechos dominicales en beneficio del interés público, y como principal novedad, introduce la segregación de las aguas marinas ${ }^{2}$, pasando ahora éstas a ser reguladas por un cuerpo legal independiente, como es la Ley de Puertos de 7 de mayo de 1880.La nueva Ley de Aguas de 1879, por tanto, centra su regulación única y exclusivamente en las aguas terrestres y se mantiene fiel e imperturbable a los principios fundamentales de su predecesora, (la Ley de 1866) tal y como puede deducirse tras la lectura de los artículos 407 a 425 del Código Civil de 1889, y especialmente en el último de dichos artículos, que declara que en todo lo que no esté expresamente prevenido por las disposiciones del capítulo $1^{\circ}$ del Título $4^{\circ}$, libro $2^{\circ}$ del Código civil, se estará a lo mandado por la Ley especial de aguas. Tienen éstas, una ley general, que es el Código civil, y dos leyes especiales, que son las de 13 de junio de 1879 (Ley de Aguas) y la Ley de 7 de mayo de 1880 (Ley de Puertos).

\section{Orígenes de la Legislación de Aguas en la España del Siglo XIX}

Los nuevos principios políticos proclamados por los legisladores de las Cortes de Cádiz declararon la libertad en el cultivo del suelo y reclamaron urgentes disposiciones

\footnotetext{
${ }^{2}$ Las aguas marinas o marítimas y las aguas terrestres eran reguladas en bloque por la Ley de aguas de 3 de agosto de 1866. La nueva Ley de Aguas de 13 de junio de 1879 segrega las aguas marinas, pues entiende el legislador que las aguas marítimas se diferencian de las terrestres, tanto por su propia y peculiar naturaleza, como por los usos y aprovechamientos a que se destinan, y por los distintos derechos que se derivan de su dominio, se ha creído oportuno trasladar la aguas marinas a la Ley de Puertos.
} 
legislativas, tales como la publicación de los Decretos de Cortes de 6 de agosto de $1811 \mathrm{y}$ en el Decreto de 19 de julio de 1813,en virtud de los cuales se incorporaban a la Nación todos los señoríos jurisdiccionales de cualquier clase y condición que fuesen y del mismo modo, se abolían los privilegios de pesca, caza, construcción de molinos y aprovechamientos de aguas, quedando al libre uso de los pueblos conforme al derecho común y reglamentos municipales establecidos. Estas disposiciones en unión con las de 8 de junio de 1813 vinieron a declarar que los dueños de heredades, dehesas y demás tierras, de cualquier clase, eran libres de destinarlas a pastos para el ganado, cultivo o cualquier otro uso que tuvieran a bien. La consecuencia directa de este Decreto fue el aprovechar las aguas como parte integrante del suelo, y las disposiciones que se dictaron sobre aprovechamiento de las aguas con fuerza motriz en la construcción de molinos y otros artefactos.

Siguiendo la senda de las reformas en la distribución y aprovechamiento de las aguas, la Real Orden de 5 de abril de 1834 vino a señalar que no se podían distraer las aguas de los ríos o manantiales que desde tiempos antiguos regasen otros terrenos más bajos, respetándose los derechos los derechos adquiridos. Esta medida llevó la tranquilidad a los poseedores de esta clase de aprovechamientos y sirvió de estimulo para acometer nuevas obras en vista del respeto que se ofrecía al derecho de prioridad en la aplicación del agua.

El 22 de enero de 1852 se creo una Comisión para que se formulase el proyecto de una ley general. Ese proyecto alcanzó fuerza de Ley el 3 de agosto de 1866. Pese los importantes avances y progresos que introdujo la Ley de Aguas, tal y como ya hemos podido comprobar, fue sin embargo, suprimida por el Decreto de 14 de noviembre de 1868, en el que se resuelven cuestiones de suma importancia con diferente criterio que el que sirvió de pauta para la Ley de Aguas de 1866 y posteriormente, con la Ley de 20 de febrero de 1870 y el Reglamento para su aplicación, se alteró también esencialmente aquélla, pues no era pocas la voces que afirmaban que en España no existía una sola Ley de Aguas sino varias leyes de Aguas. Esto fue lo que provocó el surgimiento de corrientes que exigían una nueva reforma de la Ley de Aguas. Así se hizo por el Gobierno, publicando la nueva Ley de Aguas de 13 de junio de 1879, la cual tuvo muy presente las innovaciones que en la materia introdujeron las bases para la nueva legislación de Obras públicas de 29 de diciembre de 1876 y la subsiguiente Ley general de Obras de 13 de abril de 1877.

Esta nueva Ley de Aguas de 13 de junio de 1879, mantienen los mismos principios fundamentales y en esencia el mismo espíritu normativo que su antecesora, si bien es cierto, introduce algunas novedades importantes, como la segregación de las aguas marítimas, ya que la nueva Ley de Aguas a diferencia de su antecesora, donde convivían bajo un mismo techo legal, tanto las aguas terrestres como las marítimas, ahora tras la reforma, las aguas marinas pasan a ser reguladas por un cuerpo legal distinto e independiente a la Ley de Aguas, surge así, la Ley de puertos de 7 de mayo de 1880. La razón principal que empujó al legislador a tomar esta decisión tan radical, no fue otra, que la de mantener un adecuado nivel de coherencia, claridad e uniformidad legislativa, contribuyendo de este modo a un fácil manejo de la Ley de Aguas.

El legislador, fiel por tanto a su razonamiento práctico y coherente, entendió bien que las aguas marítimas se diferencian claramente de las aguas terrestres, tanto por su propia y peculiar naturaleza como por los usos y aprovechamientos a que se destinan unas y otras. Y del mismo modo, por los distintos derechos que se derivan de su dominio, se creyó oportuno trasladar la regulación de las aguas marítimas a la Ley de Puertos de 1880, dejando para la nueva Ley de Aguas de 1879 la regulación de las aguas terrestres, ya sean 
éstas de carácter superficial, como las aguas de los ríos, arroyos, pantanos, entre otros, o de aguas interiores, como serías las aguas subterráneas, de manantiales, pozos, acuíferos, entre otros. Con la Ley de Puertos y el Reglamento para la ejecución de las aguas puede decirse que se ha abierto las puertas hacia la gran codificación española en materia de aguas, llamada a ejercer una gran influencia en el desarrollo y prosperidad de la riqueza pública de España.

\section{Aspectos preliminares al estudio de los aprovechamientos de las aguas públicas: Clasificación de las aguas en la Ley y breve análisis conceptual (de aprovechamiento, uso y dominio de las aguas)}

En la Ley de aguas de 13 de junio de 1879, el líquido elemento se nos presenta como un bien colectivo que ha de destinarse a la satisfacción de las necesidades generales. Las aguas en base a la presente Ley pueden ser clasificadas por el lugar que ocupan en; marítimas o aguas marinas y terrestres. Dentro de las aguas marinas hay diferenciar a su vez; las aguas de alta mar, que son aquellas que no pertenecen a nadie; las zonas marítimas o mar litoral, que son aquellas que pertenecen al Estado y por último, las zonas marítimo-terrestres, que por regla general son de dominio público, siempre y cuando los terrenos de esta zona sean propiedad del Estado. Por su parte, las aguas terrestres, se clasifican a su vez atendiendo a tres criterios ${ }^{3}$ : por su propiedad, en aguas públicas o de dominio público- art 407 del C. Civil- y privadas o de dominio privado -art 408 del C. Civil- (estos conceptos serán objeto de estudio más adelante).

Si atendemos al origen de las aguas, éstas se clasifican a su vez en: pluviales, (aguas que proceden de las lluvias), en aguas vivas (constituidas por manantiales), en aguas corrientes, tales como la de los ríos, torrentes y arroyos, (se caracterizan éstas por estar en constante movimiento), en aguas muertas o estancadas, tales como la de los lagos, lagunas y charcas, y por último tenemos las aguas subterráneas, que son aquellas que discurren por el interior de la tierra, cuyas aguas pueden aflorar al exterior, bien de forma natural o bien por obra del hombre (un ejemplo de estas aguas son: los acuíferos, pozos y manantiales). La tercera y última de las categorías de aguas terrestres que prevé la Ley en atención a su naturaleza, es la relativa a las aguas minerales, termales y medicinales, que son aquellas que por sus cualidades y naturaleza especial tienen asociados propiedades curativas para ciertas enfermedades contraídas por el ser humano. Como hemos tenido ocasión de comprobar, la citada Ley acoge en su seno a un amplio y variado abanico de categorías de aguas terrestres, atendiendo a tres criterios; por su origen, propiedad y naturaleza especial de las aguas.

Por otro lado, hemos de tener presente que el régimen jurídico en materia de aguas está constituido por normativas que regulan su utilización, uso y aprovechamiento, así como por un conjunto de derechos y deberes que se derivan del dominio de las aguas. En este sentido y como paso previo al estudio y análisis de los aprovechamientos de las aguas que prevé la Ley de 13 de junio de 1879, resulta de interés cara a la comprensión final del tema objeto de estudio, el conocer algunos concepto trascendentales que se reiteran constantemente a lo largo de la presente Ley. Estos conceptos legales son entre otros; el de uso, aprovechamiento y dominio de las aguas.

\footnotetext{
${ }^{3}$ En la Ley de Aguas de 13 de junio de 1879, las aguas terrestres quedan clasificadas en atención a tres criterios; por su propiedad, (aguas de dominio público y privadas), por su origen y naturaleza especial de las aguas.
} 
El término uso, (en el contexto de las aguas) supone servirse de una cosa, pero sin descomponerla, esto es, conservando su idea como servidumbre; (ejemplo de ello, lavarse o bañarse supone un uso del agua) mientras que el concepto de aprovechamiento (en el mismo contexto que en el caso anterior) supone el derecho por ley, concesión o prescripción de utilizar para usos comunes o privadas aguas de dominio público .En los supuestos de aguas de dominio privado, su uso no es más que una de las facultades inherentes al derecho de propiedad, siendo posible, también el aprovechamiento de las mismas por persona distinta de su propietario. Por contra, cuando se trata de aguas de dominio público, pese a que la Administración pueden utilizarlas por si mismo, el aprovechamiento se realizará por un administrado o por un organismo distinto a la propia Administración del Estado que se sujetará al régimen general de las utilizaciones demaniales (Álvarez Fernández, 2004).

En cuanto al dominio de las aguas si lo comparamos con el concepto de uso y aprovechamiento, la diferencia es clara, pues el dominio es un derecho absoluto e ilimitado por el que estamos autorizados para disponer o hacer de un bien lo que creamos conveniente, con un único límite, el de no perjudicar el derecho de los demás El dominio o derecho de propiedad, es un derecho real que atribuye a su titular la facultad de gozar y disponer de una cosa o bien sin más limitaciones que las establecidas por ley. El aprovechamiento, es por el contrario, un derecho limitado, sujeto a las condiciones del que lo concede.

Debemos tener en cuenta que la naturaleza del dominio influye lógicamente en la del aprovechamiento; por esta razón, es público o particular, según que el bien sea de dominio nacional o particular.

En la Exposición de motivos de la Ley de Aguas de 1879, podemos distinguir hasta dos tipos de aprovechamientos: por un lado, los que "son inherentes a la naturaleza pública del agua, comunes por tanto, a todos, y que no exigen autorización o concesión especial, puesto que se limitan a usar de las corrientes sin consumirlas ni impedir iguales aprovechamientos por parte de otros" y por otro lado,"los que consumiendo el agua o impidiendo que otros la aprovechen en el mismo punto y de la misma manera, exigen concesiones especiales por parte del poder encargado de mantener el orden y procurar la armonía en el disfrute de toda clase de aprovechamiento público". En el primer caso, la Ley se está refiriendo a los aprovechamientos comunes y en el segundo caso, a los aprovechamientos especiales (ambos aprovechamientos de las aguas recibirán el correspondiente análisis a lo largo del presente trabajo) ${ }^{4}$. Para cerrar este círculo conceptual y como preámbulo al estudio del tema a desarrollar resultaría de interés diferenciar entre el dominio público y dominio privado de las aguas.

Respecto al carácter público o privado de las aguas una Sentencia de 25 de abril de 1959 vino a señalar que la naturaleza especial de las aguas, si por sus caracterizas físicas, movilidad, forma o lugar en el que se manifiestan o encuentran, como por las múltiples necesidades que pueden satisfacer, hace necesario la existencia de un régimen jurídico especial, que atendiendo al cumplimiento de tan diversos fines sociales, respetasen a su vez el dominio exclusivo y excluyente de aquellos otras, sobre las que no existen razones que determinen el apartarlas de la general regulación de las propiedad; aguas de dominio y aguas

\footnotetext{
4 Massó Escofet (1956) en el “ Tratado de la Legislación de Aguas públicas y privadas” recoge como diferencia entre el concepto de uso y el de aprovechamiento, el hecho de que el uso se somete a prescripciones invariables a las que han de sujetarse los usuarios, por contra, los aprovechamientos, permite a los órganos administrativos fijar para cada uno de los peticionarios diferentes condiciones y modalidades de otorgamiento "en orden a las circunstancias que pueden ofrecer las corrientes, las condiciones topográficas, los cultivos a los que debe de aplicarse...etc. "
} 
de dominio privado, quedan, pues perfectamente diferenciadas por la Ley de Aguas y sometidas a distinto trato jurídico, tanto en la amplitud de los derechos que sobre cada una de ellas pueden ostentarse que sobre la forma de adquisición de los mismos.

Constituye pues, el dominio público, el conjunto de bienes que siendo propiedad de un ente público están afectos a un uso o a un servicio público. Son inalienables, imprescriptibles e inembargables. En este sentido el art 4 de la Ley de Aguas de 1879, en clara sintonía con el art 407 del Código Civil, dice al respecto que "Son públicas o de dominio público: $1^{\circ}$-Las aguas que nacen continua o discontinuamente en terrenos de mismo dominio. $2^{\circ}$ - Las aguas continuas o discontinuas de manantiales y arroyos que corren por cauces naturales. $3^{\circ}$.Los ríos".Las aguas derivadas de un río no pierden nunca su carácter de aguas públicas y en este sentido se pronuncia una sentencia de 13 de abril de 1881: Las aguas derivadas de un río no pierden nunca el concepto de públicas, aunque se tomen de una acequia de riego y aunque sea después de haberse utilizado para el movimiento de un establecimiento industrial. Siendo de dominio público las aguas de los ríos y sus cauces, lo son las que se bifurcan momentáneamente abriendo nuevo cauce por terrenos particulares para volver al río, a no ser que este nuevo cauce quede en seco por obra de la naturaleza o por virtud de trabajos practicados "ad hoc". Siguiendo con el carácter público de las aguas y en virtud del Decreto 7 de abril de 1879, establece al respecto que cuando las aguas no han salido de su cauce natural o se discute sobre su primera distribución, deben de ser clasificadas de públicas. Del mismo modo, el brazo o ramal de un río que atraviesa un terreno particular, sigue siendo de dominio público y no pertenecen al dueño del terreno, porque no deja de formar parte del río de que procede. Si las aguas se apartan artificialmente de su curso natural, se considera que el cauce y los márgenes del acueducto que las conduce, son parte integrante de la heredad o edificio a que van destinadas, de donde se sigue que el acueducto no es de dominio público, sino de los que son dueños de la fábrica de que forman parte. (Sentencia del Tribunal Supremo de 27 de mayo de 1896).

Por contra, son privadas o de dominio privado aquellas aguas que existen o discurren en terrenos de propiedad privada y que por tanto, pertenecen a uno o varios particulares en virtud de un título. En este sentido, dice el artículo primero de la Ley de Aguas que "Pertenecen al dueño de un predio, las aguas pluviales que caen en el mismo, mientras discurran por él. Podrá, en consecuencia, construir dentro de su propiedad estanques, pantanos, cisternas, o aljibes donde conservarlas al efecto, o emplear cualquier otro medio adecuado, siempre que con ello no cause perjuicio al público ni a terceros". Esta limitación es tan natural como justa y se funda en el principio jurídico de que es lícito hacer todo aquello que a uno aprovecha y que a nadie daña. Comparando este artículo con su equivalente de la Ley de 1866, se advierten algunas diferencias que conviene explicar. Su redacción ha mejorado, porque no sólo enumera los receptáculos que pueden emplearse para conservar las aguas de lluvia, sino que añade la frase de "cualquier otro medio adecuado, con lo que se evitan las cuestiones que pudieran surgir sobre si está

\footnotetext{
5 Igual criterio sostiene la sentencia de 22 de noviembre de 1888, auque con alguna matización singular:“Son de dominio público, las aguas de los ríos, las pluviales que discurran por barrancos o ramblas, cuyos cauces sean de dominio público, así como los cauces, en cuyo concepto, las que no han dejado de formar parte del río no pueden estimarse de dominio particular, auque corran por otro cauce abierto naturalmente por el río en terrenos de dominio privado, según el texto expreso de la Ley, a menos, que en este último caso, que ya por obras de la naturaleza, ya por virtud de trabajos al efecto, quede nuevamente en seco el terreno por donde se abrió el nuevo cauce".
} 
comprendido en el artículo el caso de valerse de algún otro medio no enumerado en él. Aunque en la Ley de 1866 se decía "que cae o se recogen" y en la actual se ha suprimido, no supone que tenga por objeto limitar el derecho de esta clase de aguas. Vemos por último, como las aguas que discurren por los cauces naturales de los ríos y arroyos son de dominio público y no pierden su cualidad y adquieren la condición de aguas privadas, hasta que, separadas de su cauce natural, penetren en los caudales, acequias y acueductos de dominio privado, según se deduce de los artículo 407 y 408 del Código Civil y artículos $1^{\circ}$, $4^{\circ}, 5^{\circ}$ y 98 de la Ley de Aguas.

\section{Aprovechamientos de las aguas públicas en la Ley de Aguas de 1879. Aspectos generales}

En la citada Ley de Aguas, los aprovechamientos de las aguas públicas se clasifican en aprovechamientos comunes y especiales. Bajo la primera categoría quedarían comprendidos los aprovechamientos de las aguas públicas para un uso común, tales como; la pesca, la navegación y la flotación, así como para un uso especial; por ejemplo; para servicio doméstico, servicio agrícola, servio fabril, entre otros. Junto a los aprovechamientos comunes de las aguas públicas, tendríamos los aprovechamientos especiales (para abastecimiento de poblaciones, para abastecimientos de ferrocarriles, riegos, viveros y criaderos de peces, canales de navegación, puentes y establecimientos industriales, entre otros. Por aprovechamientos comunes de las aguas públicas, por regla general se entiende la utilización de las aguas para satisfacer las necesidades generales sin que ello suponga un menoscabo o quebranto para el usuario por el hecho de ser utilizada por los demás partícipes. Un ejemplo de ello sería, extraer aguas para abrevar o bañar animales, entre otros. La utilización o uso de las aguas públicas reviste el carácter de un derecho público e inherente al individuo con independencia de su origen o nacionalidad. Por su parte, los aprovechamientos especiales desde un punto de vista legal, comprende los que técnicamente son utilizaciones privativas de las aguas. Este tipo de aprovechamiento tiene como nota característica, el hecho de requerir una previa concesión administrativa, ya sea expresa o tacita. Cualquier particular puede adquirir el derecho al aprovechamiento de las aguas públicas durante un determinado periodo de tiempo que prevea la Ley en virtud de la prescripción adquisitiva o usucapión.

Por otro lado, el Código Civil en su artículo 409 estable que "el aprovechamiento de las aguas públicas se adquiere: $1^{\circ}$. Por concesión administrativa, $2^{\circ}$. Por prescripción de veinte años. Los limites de los derechos (reales) y obligaciones de estos aprovechamientos serán los que resulten, en el primer caso de los términos de la concesión y en el segundo, del modo y forma en que se haya usado de las aguas". Como el agua es susceptible de muchos aprovechamientos tal y como hemos tenido ocasión de comprobar, es preciso que la Ley fije el orden de preferencia en que deben de hacerse las concesiones, teniendo en cuenta para ello la mayor o menor necesidad y utilidad de la nueva aplicación. Debemos tener presente que una concesión no deja de ser un acto administrativo por el cual se otorga a un individuo determinado derechos que antes no disfrutaba. $O$ dicho con otras palabras, se trata de un acto jurídico unilateral de la Administración que consiste en una declaración de voluntad, de juicio, de conocimiento, o de deseo realizada por la Administración en ejercicio de una potestad administrativa distinta de la potestad reglamentaria. Las concesiones se entienden hechas sin perjuicio de terceros y dejando a salvo los derechos de los particulares. La Ley fija las reglas generales sobre la concesión de aguas públicas y fija un orden de prelación entre los diferentes aprovechamientos, tal y como hizo la Ley de Aguas 1866. 
En este sentido, dice el art 160 de la Ley de Aguas de 1879 (art. 207 en la Ley de 1866) "En las concesiones de aprovechamientos especiales de aguas públicas se observará el siguiente orden de preferencia: $1^{\circ}$-Abastecimiento de poblaciones. $2^{\circ}$-Abastecimiento de ferrocarriles. $3^{\circ}$ - Riegos. $4^{\circ}$ - Canales de navegación $5^{\circ}$ - Molinos y otras fábricas, barracas de paso y puentes flotantes. $6^{\circ}$ - Estanques para viveros o criaderos de peces. Tras fijar este orden de preferencia, a continuación el citado artículo, viene señalando que en la concesión de toda clase de aprovechamientos de aguas públicas deben de ser preferidas las Empresas de mayor importancia y utilidad, y en igualdad de circunstancias, las que antes hubieren solicitado el aprovechamiento, por lo que se ve que la prioridad en la solicitud únicamente da derecho preferente a la concesión cuando se trate de peticiones igualmente útiles e importantes, pero no cuando la importancia y utilidad de las peticiones sea distinta y una de ellas superior a las demás que se hayan podido formular.(Sentencia de 23 de junio de 1898).

\section{Los aprovechamientos comunes de las aguas públicas en la Ley de Aguas}

Los aprovechamientos comunes de las aguas públicas quedan comprendidos dentro del Título IV de la Ley de Aguas de 13 de junio de 1879, cuya regulación queda circunscrita en los artículos 126 a 146 de la citada Ley. Se entiende por aprovechamientos comunes de las aguas públicas; "los inherentes á la naturaleza pública del agua, comunes por tanto, á todos, y que no exigen autorización ó concesión especial, puesto que se limitan a usar de las corrientes sin comunicarlas ni impedir iguales aprovechamientos por parte de otros". De esta definición podemos extraer algunas notas o conclusiones que pueden ser de gran utilidad para captar mejor el sentido de este tipo de aprovechamiento. Podemos observar de esta definición de aprovechamiento como se materializa en la misma, el principio general de que todo bien público (las aguas, en este caso) pertenecen a todos y cualquier individuo puede ejercer su derecho a usar y disfrutar de él, de la forma que crea más conveniente, sin que tal uso menoscabe o implique un perjuicio al derecho de los demás a usar y disfrutar del bien común. Una vez aclarado este punto, pasemos a ver algunos aspectos importantes que la Ley de Aguas reserva a estos aprovechamientos.

En primer término, la Ley en su Título IV, Capítulo X, "De los aprovechamientos comunes de las aguas públicas" hace la siguiente subdivisión de apartados; Del aprovechamiento de las aguas públicas para el servicio doméstico, agrícola o fabril' (Sección Primera del Título IV de la Ley), Del aprovechamiento de las aguas publicas para la pesca (Sección segunda del Título IV de la Ley),Del aprovechamiento de las aguas para la navegación y flotación (Sección Tercera ).Por lo que respecta al aprovechamiento de las aguas públicas para el servicio doméstico, agrícola o fabril ( art 126 a129 de la LA), se prevé que mientras las aguas discurran por sus cauces naturales y públicos, todos podrán usar de ella para beber, lavar las ropas vasijas y cualesquiera otros objetos, bañarse o bañar caballerías y ganados, con la sola sujeción a los Reglamentos y Bandos de la Policía municipal.

En los canales, acequias o acueductos de aguas públicas al descubierto, aunque de propiedad temporal de los concesionarios, todos podrán lavar ropas, vasija u otros objetos, pero no se podrán bañar ni abrevar ganados ni caballerías sino precisamente en los sitios destinados a este objeto ${ }^{6}$. Respecto a los aprovechamientos de aguas públicas para la navegación y flotación, así como para pesca. Considerados los ríos como grandes vías de comunicación, es indudable que la navegación y flotación son los aprovechamientos de las

\footnotetext{
${ }^{6}$ Véase artículos 127 y ss. de la Ley de Aguas de 13 de junio de 1879
} 
aguas que más pueden influir en la prosperidad de un territorio, pues contribuyen a la continua comunicación de los productos. La Ley establece que compete al Ministerio de Obras Públicas (o al Gobierno a propuesta de aquél) mediante expediente declarar a través de Reales Decretos, navegables y flotables los ríos y embalses. Para alcanzar este objetivo, podrá expropiarse cuantos terrenos se crean convenientes para ello, e incluso, aprovechamientos especiales (concesiones para riegos, entre otros).En cuanto al aprovechamiento de las aguas públicas para pesca (art 129 a 133) la Ley prevé que cualquier persona puede pescar en los cauces públicos, sujetándose a las leyes y reglamentos de policía que especialmente sobre la pesca puedan dictarse, siempre que no afecte a la navegación y flotación. Por otro lado, merece especial atención la cuestión de que en las aguas de dominio privado y en las concedidas para el establecimiento de viveros o criaderos de peces, tan sólo podrán pescar los dueños o concesionarios, sin más restricciones que las relativas a la salubridad pública (art 133-135 LA).

\section{Los aprovechamientos especiales de aguas públicas en la Ley de Aguas de 1879. Nociones básicas en tono a los aprovechamientos especiales para el riego}

La citada Ley de Aguas regula los aprovechamientos especiales de las aguas públicas en su Capítulo XI del Título IV (arts. 147 a 225 de la Ley). La sección Primera del Capítulo XI, se preocupa de "La concesión de aprovechamientos", la Sección segunda, "Del aprovechamiento de las aguas públicas para el abastecimiento de poblaciones". La Sección tercer "Del aprovechamiento de las aguas públicas para el abastecimiento de ferrocarriles", la Sección Cuarta "Del aprovechamiento de las aguas públicas para riegos", la Sección Quinta "Del aprovechamiento de las aguas públicas para canales de navegación", Sección sexta "Del aprovechamiento de las aguas públicas para barcas de paso, puentes y establecimientos industriales, y la Sección Séptima "Del aprovechamiento de las aguas públicas para viveros o criaderos de peces".

Son aprovechamientos especiales "Los que consumiendo el agua o impidiendo que otros la aprovechen en el mismo punto y de la misma manera, exigen concesiones especiales por parte del poder encargado de mantener el orden y procurar la armonía en el disfrute de toda clase de aprovechamientos públicos" ". De esta definición queda claro que la nota que caracteriza y a su vez diferencia a estos aprovechamientos especiales de los comunes es la exigencia de concesiones especiales (otorgadas a los particulares por parte de la Administración o cualquier otro organismo público) cuyo efecto es otorgar al titular de la concesión plenas facultades de uso y disfrutes respectos de las aguas públicas para su aprovechamientos, previo pago de unas tasas, fijándose de este modo, límites respecto a su uso para los particulares ajenos a tal concesión (Aurelio Guaita). Por tanto, dice la Ley, que "es necesaria la previa autorización para el aprovechamiento de las aguas públicas, especialmente destinadas a Empresas de interés público o privados, en la forma y con los requisitos que allí se determinen" (art 147 LA). Por regla general, estos aprovechamientos especiales se hallan sujetos a la previa obtención de un título concesional, pero se admite de igual modo, la prescripción de veinte años, como ya había hecho la Ley de 1866, ante la necesidad de respetar la gran variedad de aprovechamientos existentes, que sin embargo, no podían acreditarse con un título expreso (Explosión de Motivos de la Ley de 1866)

Ley de Aguas de 1879 prevé un amplio y variopinto abanico de aprovechamientos especiales de aguas públicas, tal y como hemos tenido ocasión de comprobar, y todas ellas

\footnotetext{
${ }^{7}$ Alcubilla. Diccionario de la Administración. Página 471.
} 
si duda alguna han influido de forma decisiva en el desarrollo socio-económico del país. Si bien, mi propósito a lo largo de este trabajo, es abordar y centrar el estudio entorno al aprovechamiento de las aguas públicas destinadas única y exclusivamente al riego, pero no quiero con ello restar ni un ápice de importancia y valor al resto de aprovechamientos que prevé la Ley. La razón de este proceder es básicamente el enfatizar la enorme influencia que sin dada tuvo la Ley en el cambio de la economía agraria del país a través de la expansión de los riegos, pues el interés general de promover el aprovechamiento de las aguas para alcanzar ese propósito quedó ya patente en la Exposición de Motivos del Real Decreto de 29 de abril de 1860.

El legislador considera el aprovechamiento de las aguas y la expansión de los riegos como una de las medidas o principios fundamentales entorno al cual ha de girar la economía agrícola del país para alcanzar el nivel de progreso y bienestar deseado, (...) Sin riegos, ni son posibles en la mayor parte de nuestro territorio los prados artificiales, tan necesarios para que la ganadería deje de tener una existencia precaria, ni se puede tener una buena alternativa de cosechas que sostenga y aumente la fertilidad del suelo y la riqueza del pais. Por estas causas, la conveniencia de procurar el mayor aprovechamiento posible de las aguas es considerado como uno de los principios fundamentales de la economia agrícola, pues es una prueba irrecusable en la diferencia de valores que existe entre los terrenos de secano y los de regadio. La desproporción verdaderamente notable que hay entre los precios de uno y de otros da idea de la altura que podría llegar uno de los ramos más importantes de la riqueza pública, si pasasen á ser de la segunda clase gran parte de las tierras de boy pertenecen á la primera". En efecto, en dicha exposición de motivos existe un enorme interés por dar un giro a la política agraria que se practicaba hasta el momento, se pretende por tanto, potenciar el cultivo de regadío, en detrimento del cultivo tradicional de secano y para ello, se requiere un planteamiento lógico de aprovechamiento de las aguas, pues la optimización, aprovisionamiento y uso eficiente y responsable de las aguas hace viable la transición del cultivo de secano al de regadío, lo que se traduce en un cambio de tendencia económica, pues se pasa de país pobre y atrasado a un país que empieza a ver un horizonte de progreso y bienestar.

Se observa pues que el citado Decreto abre el camino hacia el progreso para España, tomando como punto de partida la necesidad de hacer un adecuado aprovechamiento de los recursos hídricos, pues ello posibilitará la transformación de la economía del país. En esta línea, el citado Decreto-Ley augura que el progresivo desarrollo de un buen sistema de aprovechamiento de aguas impulsará considerablemente la industria proporcionando motores para sus fábricas; abrirá nuevos medios de comunicación para el cambio de toda clase de productos, y en especial satisfará la mayor y más urgente necesidad de la agricultura con el fomento de los riegos. Queda bien definido el camino que se ha de seguir para alcanzar los objetivos marcados, pues no son otros que; impulsar la industria, transformar la agricultura del país a través del desarrollo y expansión de los campos de regadío, así como favorecer el intercambio de productos (industriales y/o agrícolas) a través de nuevos medios de comunicación, para lo cual la navegación por ríos y la apertura de nuevos trazados de vías fluviales será un elemento capital para alcanzar los objetivos marcados.

Hasta la publicación de la Ley de Aguas de 1866 puede decirse que en España, pese a los numerosos esfuerzos de los distintos Gobiernos por dictar disposiciones parciales para aplicar las aguas al riego de las tierras, la legislación presentaba un gran vacío, porque estaban aún por resolver las cuestiones más importantes sobre esta materia. Es más, la Comisión que redactó la Ley de Aguas de 1866 entendió que para dar seguridad a los capitales empleados en fomentar los riegos, bastaba tan sólo aplicar a las aguas pluviales el

\footnotetext{
${ }^{8}$ Véase el Real Decreto de 29 de abril de 1860.
} 
principio de justicia, de equidad y de conveniencia pública que respecto a los manantiales proclamó la Real Orden de 5 de abril de 1834. Debemos tener presente que la concesión de aprovechamientos de aguas públicas para riego, ofrece en virtud de la Ley de Aguas de 13 de junio de 1879 dos modalidades: la concesión para riego de tierras propias y la concesión a empresas dedicadas al riego de tierras ajenas. Si bien ambas modalidades tienen en común la necesidad de construir obras hidráulicas permanentes como presas, azudes, canales de riegos, etc., para derivar, canalizar y tomar aguas. Pero se diferencian en que las concesiones para el riego en tierras propias se hacen a perpetuidad, mientras que las otorgadas a empresas de riego son por el plazo de noventa y nueve años, transcurrido el cual las tierras quedarán libres del pago del canon y pasarán a la Comunidad de Regantes el dominio colectivo de las presas, acequias y demás obras exclusivamente precisas para los riegos (art. 188 LA).

Por lo que respecta a las empresas de canales de riego en virtud del art 194 de la presente Ley, concede a éstas una serie de beneficios tales como: $1^{\circ}$-El derecho a abrir canteras, recoger piedras sueltas, construir hornos de cal, yeso y ladrillo, así como depositar efectos o establecer talleres para la elaboración de materiales en los terrenos contiguos a las obras, entendiéndose con el dueño o indemnizando daños y perjuicios. $2^{\circ}$-La exención de los derechos que devenguen las traslaciones de dominio ocurridas en virtud de la ley de Expropiación. $3^{\circ}$ - La exención de toda contribución a los capitales que se inviertan en sus obras. Por otro lado, será obligación de las empresas de canales de riego conservar las obras en buen estado durante el tiempo de la concesión y si éstas se inutilizarán para el riego, dejarán las tierras de satisfacer el canon establecido mientras carezcan del agua estipulada, y el Ministerio de Fomento fijará un plazo para la reconstrucción o reparación. Trascurrido el plazo sin haber cumplido el concesionario, a no mediar fuerza mayor, caducará la concesión (art. 196). Por último, en interés general del mejor aprovechamiento de las aguas, dice la Ley en su artículo 204, dispondrá el Ministerio de Fomento que se proceda al reconocimiento de los ríos existentes, con objeto de que ningún regante desperdicie el agua de su dotación, que pueda servir a otro necesitado de ella. Vemos como la Ley se preocupa por optimizar los recursos hídricos y posibilitar de igual modo un reparto justo y equitativo del agua, para que este recurso natural pueda ser aprovechado por todos sin que se desperdicie ni una sola gota.

\section{Conclusiones}

Hemos venido observando a lo largo de estas páginas, como la amplia variedad de aplicaciones que tiene el agua y que se han visto multiplicados con los avances y progresos de las civilizaciones a lo largo de la historia es causa y origen de muchos derechos y obligaciones, de ahí la necesidad de preceptos que definan, delimiten y determinen unos y otros, en cuanto al aprovechamiento, uso y distribución de las aguas.

Podemos afirmar que el régimen jurídico español en materia de aguas está constituido por normas que regulan las utilización, uso, distribución y aprovechamiento de las aguas, pero también regula el conjunto de derechos y deberes que se derivan del dominio de las mismas. En este sentido, la Ley de Aguas 13 de junio de 1879 cumplió con enorme solvencia con los propósitos citados, ya que influyó en gran medida en el desarrollo de la industria y agricultura del país, muy especialmente en la expansión de los regadíos, porque el empleo del agua para este fin ha sido tradicionalmente el mayor consumidor de este recurso natural, lo que ha motivado una regulación detallada y minuciosa por parte de la Ley, y ello se debió al hecho de que como bien ha venido a señalar Emilio P. Pérez (1992, 
1993), la Ley de Aguas de 1879 permitió consolidar las bases de una ordenación de los aprovechamientos de las aguas, fijando para ello, reglas sólidas en cuanto a la correcta distribución y gestión del líquido elemento a través de la Comunidad de Regantes.

Por último, quisiera resaltar que esta Ley se nos presenta como una verdadera ley general en materia de aguas, y no como una mera ley especial sobre aprovechamientos de las aguas públicas. Distingue con claridad entre aguas de dominio (público y privado) y el aprovechamiento (común o especial) de las mismas. Pero además, se halla claramente animada por el deseo de restringir los derechos dominicales en beneficio del interés general. Porque el agua es mucho más que un factor de producción, tal y como se desprende de su Exposición de Motivos, es como señaló Joaquín Melgarejo (2002) "un activo socioeconómico de carácter básico que influye en el desarrollo de toda sociedad" y que debe de ser usada y aprovechada de la manera más eficiente para que pueda reportar un beneficio ya no sólo individual sino a nivel general, en la medida en que el liquido elemento, se nos presenta como una riqueza colectiva que debe de destinarse especialmente a la satisfacción de las necesidades generales del país.

\section{Referencias}

Álvarez Fernández, M. (2004): El abastecimiento de Agua en España. Madrid. ed., ThomsonCivitas, pp. 30 y ss.

Box Amorós, M. (1992): El regadío medieval en España. Época árabe y conquista cristiana. Hitos Históricos de los regadíos españoles. MAPA Universidad de Alicante, pp. 48-90.

López Barciela, C. y Melgarejo, J. Eds. (2002): El agua en la Historia de España. Publicaciones Universidad de Alicante.

Martínez Almira, M.M. (2014): El Derecho de Aguas. Malos usos y contaminación en el derecho andalusí. Congreso Internacional sobre Historia del Agua. Elche.

Massó Escofet, C. (1956): Tratado de la Legislación de Aguas Públicas y privadas. Tomos I-II. Barcelona, Ed. Bosch.

Pérez Pérez, E. (1992): Disposiciones decimonónicas sobre aguas. Ley de 1879. Hitos históricos de los regadíos Españoles. Madrid, Ministerio de Agricultura Pesca y Alimentación, pp. 183-202.

Pérez Pérez, E. (1993): Estudios jurídicos sobre la propiedad, aprovechamientos y gestión del Agua. Madrid. MOPT, pp. 30-39. 